\title{
All-cause mortality from obstructive sleep apnea in male and female patients with and without continuous positive airway pressure treatment: a registry study with 10 years of follow-up
}

\author{
This article was published in the following Dove Press journal: \\ Nature and Science of Sleep \\ 9 April 2015 \\ Number of times this article has been viewed
}

\author{
Poul Jennum ${ }^{1,2}$ \\ Philip Tønnesen' \\ Rikke Ibsen ${ }^{3}$ \\ Jakob Kjellberg ${ }^{4}$ \\ 'Danish Center for Sleep \\ Medicine, Department of Clinical \\ Neurophysiology, Glostrup Hospital, \\ Copenhagen, Denmark; ${ }^{2}$ Faculty \\ of Health Sciences, University of \\ Copenhagen, Copenhagen, Denmark; \\ ${ }^{3}$ itracks, Aarhus, Denmark, ${ }^{4}$ Danish \\ National Institute for Local and \\ Regional Government Research, \\ Copenhagen, Denmark
}

Correspondence: Poul Jennum

Danish Center for Sleep Medicine,

Department of Clinical Neurophysiology,

Glostrup Hospital, Nordre Ringvej 57,

2600 Glostrup, Denmark

Tel +4538632512

Fax +4543233933

Email poul.joergen.jennum@glo.regionh.dk
Background: More information is needed about the effect on mortality of continuous positive airway pressure (CPAP) in patients with obstructive sleep apnea (OSA), especially in women.

Methods: We employed a historical cohort study design, using data from 25,389 patients with a diagnosis of OSA selected from the Danish National Patient Registry for the period 1999-2009. We used Cox proportional hazard function to evaluate the all-cause mortality from OSA in middle-aged and elderly males and females who were treated, or not, with CPAP.

Results: Female OSA patients had a lower mortality than males, irrespective of whether they received CPAP treatment. CPAP treatment improved survival, as illustrated by the hazard ratio of $0.62(P<0.001)$. This effect was dependent on gender: CPAP had no significant effect on 20 - to 39 -year-old males and females, but the overall mortality in this age group was small. Survival was increased by CPAP in 40- to 59-year-old and $\geq 60$-year-old males, but no such effect was observed in females. Positive predictors of survival were young age, female gender, higher educational level, and low 3-year prior comorbidity as estimated by the Charlson Comorbidity Index. Negative predictors for survival were male gender, age $\geq 60$ years, no CPAP treatment, prior comorbidity, and low educational level.

Conclusion: CPAP therapy is associated with reduced all-cause mortality in middle-aged and elderly males, but no significant effect was found in females.

Keywords: middle age, elderly, gender, mortality

\section{Introduction}

Obstructive sleep apnea (OSA) is associated with increased morbidity and mortality and affects a significant proportion of the population. OSA increases the risk of cardiovascular and cerebrovascular (CVD) morbidity and mortality, ${ }^{1}$ and has been recognized as a source of attributable risk in patients with hypertension, obesity, diabetes, cardiovascular diseases, and stroke, ${ }^{2-7}$ although some studies were negative..$^{8-12}$ However, we have almost no data from more unselected patient cohorts with OSA.

Being a chronic condition, OSA has deleterious effects on patients' social functioning, employment, and quality of life, and consequently represents a societal burden arising from increased direct and indirect costs. ${ }^{13}$ Treatment with continuous positive airway pressure (CPAP) reduces the associated CVD morbidity and mortality and other consequences of OSA. ${ }^{14-16}$ These observations are based on pooled data from predominantly middle-aged males with moderate to severe sleep apnea; although 
OSA is a source of attributable risk in women and the elderly, few attempts have been made to evaluate the effect of management. ${ }^{17}$ Recent studies of small samples of patients suggest that CPAP affects CVD morbidities in women ${ }^{18}$ and elderly patients. ${ }^{19}$ Some other recent findings suggest that sleep apnea in the elderly tends to present milder clinical forms ${ }^{20}$ and that its consequences for mortality are minor, ${ }^{21}$ although other studies suggest that OSA plays an independent role, influencing mortality in subjects older than 50 years of age. ${ }^{22}$ Therefore, the effect on all-cause mortality in women and elderly subjects appears to be slight. Most studies have used CVD end points to measure the effect of CPAP, but we have recently shown that prediagnostic morbidities involve a range of comorbidities other than CVD diseases ${ }^{23}$ and, as such, that OSA may have more wide-ranging consequences. Comorbidities prior to the diagnosis of OSA have not been taken into consideration in evaluating the effect of CPAP. Furthermore, the effect of education has not been evaluated. There is therefore a need for further studies of the treatment effect with respect to all-cause mortalities of OSA, especially in women and in patients older than 60 years of age.

The aim of this study was to identify patients' all-cause total mortality after the diagnosis of OSA, to evaluate the effect of CPAP in women and men, and evaluate the potential effect after the age of 60 years, by examining national registry data for a historical cohort of patients identified and treated over a period of up to 11 years.

\section{Method}

\section{Subjects}

In Denmark, all hospital contacts are obliged to be recorded in the National Patient Registry (NPR), providing details of the time of all contacts and information about primary and secondary diagnoses. The NPR includes administrative information and details of all diagnoses, diagnostic methods (eg, polysomnography and partial polygraphy), treatment procedures (eg, CPAP or surgery), hospitalizations, and initial and follow-up ambulatory clinical contacts gathered from all public and private hospitals. It employs several international classification systems, including the International Classification of Disorders (ICD)-10. The NPR is a time-based national database that compiles data from all inpatient and outpatient contacts, which means that the data we extracted are representative of all patients in Denmark who have received a diagnosis of OSA, irrespective of other diagnoses. As data are available for the entire observation period it is possible to trace patients retrospectively and prospectively relative to the date of their diagnosis. There are two limitations to the NPR: 1) a small fraction of patients who receive their diagnosis in the primary care sector are not identified; and 2) specific clinical information, such as body mass index (BMI), the apnea-hypopnea index (AHI), CPAP compliance data, and blood pressure (BP), are not sufficiently well-recorded in the NPR - these were therefore not included in our analysis.

Using the NPR, we identified a historical cohort of patients who received a diagnosis of OSA between 1999 and 2009, consisting of all patients with ICD-10 code of G473, which were assigned after patient evaluation in each hospital (based on polysomnography and polygraphy). This study included adults for whom we had comorbidity data for the year prior to the diagnosis, so the Charlson Comorbidity Index $(\mathrm{CCI})^{24}$ could be constructed, and for whom information on education level was available. In a previous study, we compared 30,278 OSA patients with 120,506 control subjects, ${ }^{25}$ of whom 2,998 OSA patients were children. ${ }^{26} \mathrm{As}$ we primarily wanted to identify the effect of CPAP treatment in OSA, control subjects were not included in this study.

The cohort was divided into two groups on the basis of whether they received CPAP treatment within the first 2 years following the diagnosis of OSA. In Denmark, typically, the indication for CPAP treatment is an AHI exceeding 15 episodes of apnea/hypopnea per hour, or milder apnea with major comorbidities or symptoms attributable to OSA.

The exact date of a particular treatment (CPAP) was also included in this analysis; this date could have been before the diagnosis date derived from the patient register. Instead of removing patients with a CPAP treatment date before diagnosis, we considered the patients in the CPAP-treated group to have received the treatment at some point during the period, and limited all before/after analyses to before and after the year of diagnosis, instead of before and after the first treatment.

The background variables included age, gender, education, and CCI. ${ }^{27,28}$ Educational levels were the same in the CPAP and non-CPAP treatment groups (Table 1). Since these two groups differed with respect to age and gender, we could

Table I Age distribution of subjects with OSA

\begin{tabular}{lll}
\hline & $\mathbf{N}$ & $\%$ \\
\hline All & 25,389 & 100 \\
Men & 19,768 & 77.9 \\
Women & 5,621 & 22.1 \\
Age 20-39 yrs & 4,773 & 18.8 \\
Age 40-59 yrs & 13,897 & 54.7 \\
Age $\geq 60$ yrs & 6,719 & 26.5 \\
\hline
\end{tabular}

Abbreviations: OSA, obstructive sleep apnea; yrs, years. 
not treat either of them as a matched control group. Instead, we included explanatory variables to account for differences in the background variables. Age was divided in two groups (20-59 years and $\geq 60$ years). Education was evaluated as a dichotomous dummy variable, where 0 and 1 represented patients with primary education and above, respectively. The CCI was based on comorbidity data for up to 3 years before the year of diagnosis.

\section{Evaluation of mortality before diagnosis}

Morbidity and mortality data were extracted as primary and secondary diagnoses, and further subdivided into main disease groups, in accordance with the World Health Organization (WHO) ICD-10 criteria. We estimated the prediagnostic morbidity burden using the CCI ${ }^{27,28}$ For this study, we used only all-cause morbidity and mortality data.

\section{Ethics and statistical analysis}

The study was approved by the Danish Data Protection Agency. Since all data were anonymized, neither individual nor ethical approval was required. Statistical analysis was performed using SAS 9.3 (SAS, Inc., Cary, NC, USA). We used a Cox proportional hazard function to estimate the risk of dying, where the time until death was the censored left-hand side variable. The explanatory variables were age group, gender, education level beyond basic schooling, and the CCI score in the 3 years before diagnosis.

\section{Results}

We identified 25,389 patients with OSA aged 20 years or more with comorbidity data 1 year prior to diagnosis. The distribution of age and gender is shown in Table 1. As expected, most of the patients with an initial diagnosis of OSA were middle-aged, and 22\% were women. Patients younger than 20 years were not included in this analysis as mortality data from children have been presented elsewhere. ${ }^{26}$ Table 2 summarizes patient distribution for those who did or did not receive CPAP treatment by gender, age, education, and mean CCI. CPAP treatment was received by $55.0 \%$ of males and $48.9 \%$ of females within 2 years of the time of diagnosis. The proportion of patients receiving CPAP treatment rose with age, the figure being close for the two middle-aged groups but was $10 \%$ higher for middle-aged than for patients aged less than 40 years. There were no significant differences in educational level between CPAP- and non-CPAP-treated subjects. The CCI was higher for patients receiving CPAP treatment than for those not receiving it.
Table 2 Distribution of percentage prevalence of CPAP treatment, educational level, and prior morbidity, in patients with OSA not receiving and receiving CPAP treatment

\begin{tabular}{llll}
\hline & & Non-CPAP & CPAP \\
\hline $\begin{array}{l}\text { Number of patients } \\
\text { Number of patients/year }\end{array}$ & $\mathrm{N}$ & $\mid \mathrm{I}, 758$ & $13,63 \mathrm{I}$ \\
$\quad \mathrm{N}$ & $\mathrm{N}$ & 8,888 & 10,880 \\
$\quad$ Women & $\mathrm{N}$ & 2,870 & $2,75 \mathrm{I}$ \\
Men & $\%$ & 45.0 & 55.0 \\
Women & $\%$ & 51.1 & 48.9 \\
Age 20-39 years & $\%$ & 55.0 & 45.0 \\
Age 40-59 years & $\%$ & 45.0 & 55.0 \\
Age $\geq 60$ years & $\%$ & 42.9 & 57.1 \\
Education more than primary school & $\%$ & 69.4 & 69.2 \\
CCl & Mean & 0.13 & 0.15 \\
& SD & 0.49 & 0.50 \\
\hline
\end{tabular}

Abbreviations: $\mathrm{CCl}$, Charlson Comorbidity Index; CPAP, continuous positive airway pressure; OSA, obstructive sleep apnea; SD, standard deviation.

\section{Survival after an OSA diagnosis}

Survival curves for each age group with and without CPAP treatment are shown in Figures 1 and 2, respectively, subdivided by age group ( $20-59$ years and $\geq 60$ years) and gender. These curves did not control for education and CCI, and were therefore not tested for significance.

We estimated two hazard models, the first of which included independent variables for CPAP/no CPAP, gender, age, education, and CCI. To estimate whether gender and age influence survival for the CPAP and non-CPAP groups differently, we estimated a second customized model with interaction terms for CPAP, with age and gender.

In the first model (Table 3), patients who received CPAP treatment had better survival, indicated by a hazard ratio of $0.67(P<0.0001)$ when controlling for gender, age, education, and CCI. As was expected, women had lower mortality than men, older patients had higher mortality than younger patients, education was positively associated with survival, and CCI had a negative effect on survival.

In the customized model (Table 4), the contrasts in each age group revealed that CPAP treatment had no significant effect on patients aged 20-39 years $(P=0.2943)$, but the overall mortality in this age group was low. For patients aged 40-59 years, the mortality of patients receiving CPAP treatment was lower, with a hazard ratio of $0.67(P<0.0001)$; and for patients aged $\geq 60$ years, CPAP treatment had an even greater effect on mortality, with a hazard ratio of 0.62 $(P<0.0001)$. The interaction term for gender and CPAP treatment was significant and positive, indicating that women had higher mortality than men when they received CPAP treatment. 


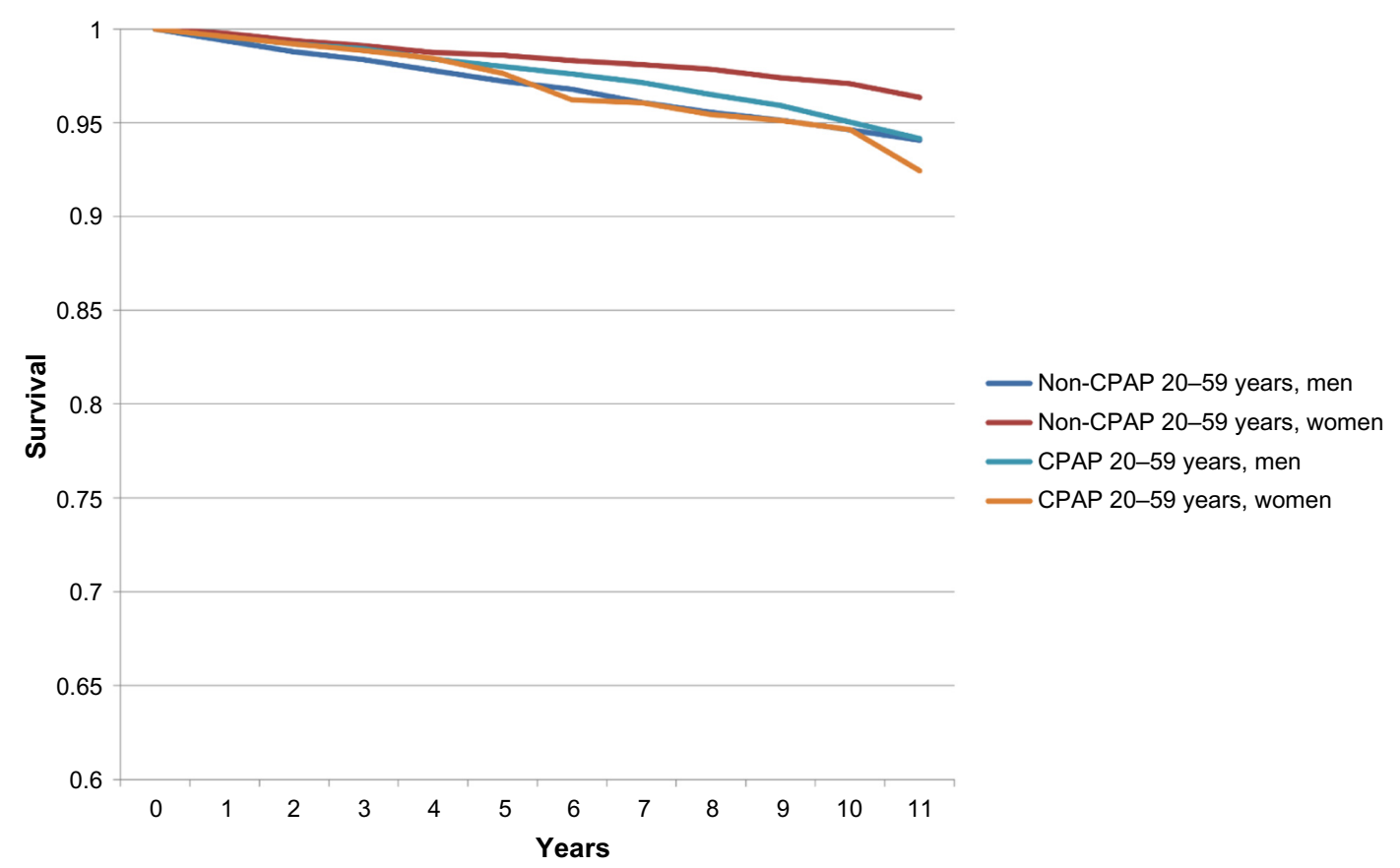

Figure I Age 20-39 years is the omitted age group.

Abbreviation: CPAP, continuous positive airway pressure.

\section{Discussion}

This study, which included patients from a national registry, revealed several important patterns: untreated OSA was strongly associated with lower survival; survival decreased with age, irrespective of gender; females had better survival than males, irrespective of whether they received CPAP treatment; higher educational level was positively associated with survival (those with higher education had better survival irrespective of whether they received CPAP treatment); prediagnostic morbidity (CCI) had a negative effect

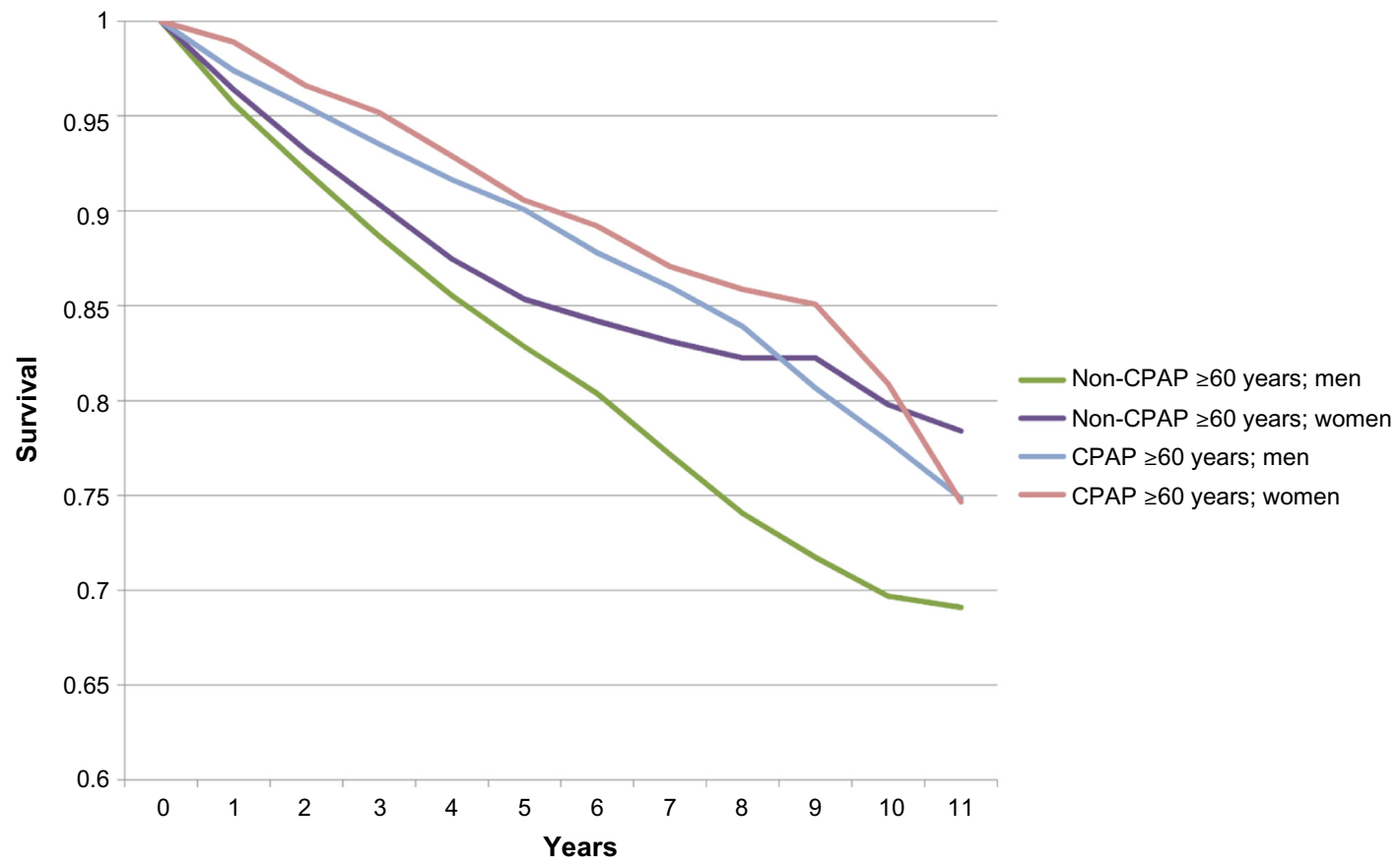

Figure 2 Survival, by age and CPAP treatment groups ( $\geq 60$ years). Abbreviation: CPAP, continuous positive airway pressure. 
Table 3 Hazard ratios of the association between mortality and gender, age group, education, $\mathrm{CCl}$, and CPAP

\begin{tabular}{|c|c|c|c|c|}
\hline & \multicolumn{2}{|l|}{ Age $\geq 20$ years } & \multicolumn{2}{|c|}{$\begin{array}{l}\text { 95\% confidence } \\
\text { interval }\end{array}$} \\
\hline & Hazard ratio & $P$ & Lower & Upper \\
\hline CPAP & 0.67 & $<0.0001$ & 0.610 & 0.746 \\
\hline Women & 0.76 & $<0.0001$ & 0.673 & 0.869 \\
\hline Age $20-39$ years & - & - & & \\
\hline Age $40-59$ years & 4.39 & $<0.0001$ & 3.236 & 5.944 \\
\hline Age $\geq 60$ years & $|5.8|$ & $<0.0001$ & 11.710 & 21.345 \\
\hline $\begin{array}{l}\text { More than primary } \\
\text { schooling }\end{array}$ & 0.64 & $<0.0001$ & 0.579 & 0.710 \\
\hline Pre-Charlson score & 1.56 & $<0.0001$ & 1.502 & 1.615 \\
\hline
\end{tabular}

Note: -Indicates the omitted age group.

Abbreviations: $\mathrm{CCl}$, Charlson Comorbidity Index; CPAP, continuous positive airway pressure.

on survival; and CPAP had a positive effect on mortality, not only in males aged $40-59$ years but also, in elderly males aged $\geq 60$ years. The hazard ratio for the younger OSA patients with CPAP was similar to that of the other age group, but the overall mortality rate in this age group was low; consequently, the effect of CPAP was small and nonsignificant. No significant association between CPAP treatment and mortality was found in females. Thus, young age, female gender, higher educational level, and a low frequency of comorbidities prior to an OSA diagnosis were all positive predictors of survival.

Table 4 Hazard ratios of the association between mortality and of gender, age group, education, $\mathrm{CCl}$ and CPAP (customized model)

\begin{tabular}{|c|c|c|c|c|}
\hline & \multicolumn{2}{|c|}{$\begin{array}{l}\text { Customized } \\
\text { model }\end{array}$} & \multicolumn{2}{|c|}{$\begin{array}{l}95 \% \text { confidence } \\
\text { interval }\end{array}$} \\
\hline & $\begin{array}{l}\text { Hazard } \\
\text { ratio }\end{array}$ & $P$ & $\begin{array}{l}\text { Lower } \\
\mathrm{Cl}\end{array}$ & $\begin{array}{l}\text { Upper } \\
\text { Cl }\end{array}$ \\
\hline CPAP & 0.72 & 0.2943 & 0.391 & 1.330 \\
\hline Women & 0.68 & $<0.0001$ & 0.569 & 0.802 \\
\hline Women CPAP & 1.32 & 0.0356 & 1.019 & 1.698 \\
\hline Age $20-39$ years & - & - & & \\
\hline Age $40-59$ years & 4.50 & $<0.0001$ & 3.063 & 6.556 \\
\hline Age $40-50$ years $*$ CPAP & 0.93 & 0.8121 & 0.493 & 1.748 \\
\hline Age $\geq 60$ years & 16.97 & $<0.0001$ & 11.475 & 24.274 \\
\hline Age $\geq 60$ years $*$ CPAP & 0.85 & 0.6219 & 0.462 & 1.608 \\
\hline $\begin{array}{l}\text { More than primary } \\
\text { schooling }\end{array}$ & 0.64 & $<0.0001$ & 0.576 & 0.705 \\
\hline Pre-Charlson score & 1.57 & $<0.0001$ & 1.516 & 1.629 \\
\hline \multicolumn{5}{|l|}{ Contrasts } \\
\hline $\begin{array}{l}\text { CPAP vs non-CPAP } \\
\text { for age } 20-39 \text { years }\end{array}$ & 0.72 & 0.2943 & 0.391 & 1.329 \\
\hline $\begin{array}{l}\text { CPAP vs non-CPAP } \\
\text { for age } 40-59 \text { years }\end{array}$ & 0.67 & $<0.0001$ & 0.561 & 0.794 \\
\hline $\begin{array}{l}\text { CPAP vs non-CPAP } \\
\text { for age } \geq 60 \text { years }\end{array}$ & 0.62 & $<0.0001$ & 0.537 & 0.707 \\
\hline
\end{tabular}

Note: -Indicates the omitted age group.

Abbreviations: $\mathrm{CCl}$, Charlson Comorbidity Index; $\mathrm{Cl}$, confidence interval; CPAP, continuous positive airway pressure; vs, versus.
OSA is a known major risk factor for cardiovascular disability in terms of morbidity and mortality, irrespective of other major cardiovascular risk factors. ${ }^{29-31} \mathrm{CPAP}$ is currently the most effective treatment for reducing associated CVD risks, including blood pressure, atherosclerotic manifestations, ${ }^{32-34}$ and mortality, ${ }^{15}$ in male subjects. The elderly have higher cardiovascular mortality rates, but CPAP may reduce this risk. ${ }^{16}$ CPAP treatment has been found to reduce mortality in women with OSA, ${ }^{18}$ a finding that is partly supported by the results of this study. We found age to be a strong risk factor for all-cause mortality and females to have a lower rate of mortality from OSA than males. In men, CPAP reduced mortality in the 40 - to 59 -year-old and the $\geq 60$-year-old age groups. However CPAP had less effect on mortality in females. These results suggest that female gender has some protective effect on the consequences of OSA relative to male gender and that the effect on excess mortality in females is weaker than in males. The small effect on all-cause mortality among 20- to 39-year-old OSA patients may be due to the overall low mortality in this age group. OSA has especially been associated with cardiovascular consequences; however, studies of comorbidities have shown the complex comorbidity $^{13,23}$ in these patients, which is why we chose to adjust for several comorbidities using the CCI.

We do not currently know why women's mortality rates were lower than those of men, but several explanations may be proposed. The prevalence of OSA is generally lower in females than in males at all ages, especially in subjects younger than 40 years of age. This suggests that incidence rates are lower in premenopausal females than in males, despite the potential negative impact of OSA on cardiovascular morbidity and mortality. ${ }^{35,36}$ As a consequence, women appear to be protected from the consequences of OSA 10-15 years earlier than are men. Patients with OSA often complain of insomnia. ${ }^{37}$ A greater arousability may protect from the severity of OSA. Other factors may include comorbid disease, cardiovascular risk, and lifestyle factors. Further evaluation of morbidities and mortality in women is needed to confirm these findings.

Our analysis was adjusted for age, gender, and other demographic variables that influence disease outcome. Women with OSA are more likely to be treated for depression, to have insomnia, and to have hypothyroidism than males with OSA. ${ }^{38-40}$ Age is also likely to have an effect, especially as a result of increasing health care use and indirect costs. Cardiovascular disease and obesity are most common in young adults and the middle-aged, whereas among elderly OSA patients the effects of medication and comorbid 
depression may add to the disease burden. ${ }^{13,23}$ Other studies have shown weaker effects of age, ${ }^{41-43}$ even if only among those with comorbid cardiovascular disease. ${ }^{21}$ Due to the limited details provided by the mortality codes available to us, we decided to use all-cause mortality and found a strong association with age but similar survival rates for men and women. This suggests that OSA involves an independent risk association among middle-aged and elderly men and women. We also recently found a higher mortality rate in children with OSA than in matched controls. ${ }^{26}$ Children may also present morbidities that correspond to higher mortality rates, but OSA, which is independent of age, appears to be a risk factor for all-cause mortality. The study also indicates that comorbid conditions are associated with lower survival in OSA patients. Further analysis should include subgroup analysis of types of morbidities, risk factors, and the influence of medication. The study also revealed that low educational level was negatively associated with survival in OSA patients.

There are several limitations of our study: it was based on retrospective clinical/hospital reports submitted to the NPR; the diagnostic accuracy depends on clinics' retrospective evaluation of presentation and reporting of the diagnosis and comorbidities; confounder variables (eg, BMI and other cardiovascular risk factors) were not recorded; and finally, symptoms and the results of clinical evaluation were not considered (eg, polysomnography, limited channel polygraphy, and cardiac evaluations), so our findings cannot be related to disease severity. The strengths of the NPR, however, are that it is a national database including all identified patients, it is time-locked (all reports must be associated with patient contacts), and it covers a substantial follow-up time. In addition, the study was controlled (although not a randomized controlled trial), leading to a potential bias toward more severe diseases among treated patients. Nevertheless, the latter factor cannot explain why males, but not females, showed a positive association. We therefore believe our findings reflect genuine and important gender differences in the consequences of OSA. As this was an observational registry study, there was no randomization with respect to CPAP in these patients with OSA. There may be several reasons for not prescribing CPAP therapy. Subjects with mild disease and/or without subjective symptoms of OSA and patients with positional OSA (ie, OSA only in supine sleep position) are probably the largest group. Most of these subjects would have an AHI below 15/hour. There is evidence that this group with mild OSA have better survival than those patients with moderate to severe OSA. This would lead to higher survival in the group not treated with CPAP, in contrast with the findings of the present study. Another factor is that we do not know anything about compliance among the patients treated with CPAP. This means that $40 \%-50 \%$ of this group might not use CPAP after 6-12 months, thereby potentially introducing a bias, reducing the possible survival benefits from CPAP. It is reported that patients not accepting CPAP have the same high compliance with drugs for elevated cholesterol, for reducing hypertension, etc. ${ }^{44}$

We conclude that CPAP treatment is associated with lower mortality rates in males with OSA, including the middle-aged and elderly (aged $\geq 60$ years). However, we found no significant effect on all-cause mortality of CPAP treatment in female OSA patients. Evaluation of female OSA should be carried out in future studies including larger groups. We have identified a special risk group with increased mortality: males with OSA older than 60 years, with comorbidities and low educational level. Interventions should be tested to try to improve CPAP compliance in this group.

\section{Author contributions}

Poul Jennum and Jakob Kjellberg were responsible for the creation, initiation and management of the project. All authors took part in the project including conception and design, data acquisition, analysis and interpretation of data, drafting of the article, and final acceptance of the manuscript, and are accountable for all aspects of the work.

\section{Disclosure}

The authors report no conflict of interests in this work.

\section{References}

1. Lavie P, Lavie L, Herer P. All-cause mortality in males with sleep apnoea syndrome: declining mortality rates with age. Eur Respir J. 2005;25(3):514-520.

2. Lavie P, Herer P, Lavie L. Mortality risk factors in sleep apnoea: a matched case-control study. J Sleep Res. 2007;16(1):128-134.

3. Korostovtseva LS, Sviryaev YV, Zvartau NE, Konradi AO, Kalinkin AL. Prognosis and cardiovascular morbidity and mortality in prospective study of hypertensive patients with obstructive sleep apnea syndrome in St Petersburg, Russia. Med Sci Monit. 2011;17(3):CR146-CR153.

4. Marshall NS, Delling L, Grunstein RR, et al. Self-reported sleep apnoea and mortality in patients from the Swedish Obese Subjects study. Eur Respir J. 2011;38(6):1349-1354

5. Shah NA, Yaggi HK, Concato J, Mohsenin V. Obstructive sleep apnea as a risk factor for coronary events or cardiovascular death. Sleep Breath. 2010;14(2):131-136.

6. Yazdan-Ashoori P, Baranchuk A. Obstructive sleep apnea may increase the risk of stroke in AF patients: refining the CHADS2 score. Int $J$ Cardiol. 2011;146(2):131-133.

7. Mansukhani MP, Bellolio MF, Kolla BP, Enduri S, Somers VK, Stead LG. Worse outcome after stroke in patients with obstructive sleep apnea: an observational cohort study. J Stroke Cerebrovasc Dis. 2011;20(5):401-405. 
8. Peppard PE, Young T, Palta M, Skatrud J. Prospective study of the association between sleep-disordered breathing and hypertension. $N$ Engl J Med. 2000;342(19):1378-1384.

9. Mills PJ, Kennedy BP, Loredo JS, Dimsdale JE, Ziegler MG. Effects of nasal continuous positive airway pressure and oxygen supplementation on norepinephrine kinetics and cardiovascular responses in obstructive sleep apnea. J Appl Physiol (1985). 2006;100(1):343-348.

10. Faccenda JF, Mackay TW, Boon NA, Douglas NJ. Randomized placebocontrolled trial of continuous positive airway pressure on blood pressure in the sleep apnea-hypopnea syndrome. Am J Respir Crit Care Med. 2001;163(2):344-348.

11. Minoguchi K, Yokoe T, Tanaka A, et al. Association between lipid peroxidation and inflammation in obstructive sleep apnoea. Eur Respir J. 2006;28(2):378-385.

12. Babu AR, Herdegen J, Fogelfeld L, Shott S, Mazzone T. Type 2 diabetes, glycemic control, and continuous positive airway pressure in obstructive sleep apnea. Arch Intern Med. 2005;165(4):447-452.

13. Jennum P, Kjellberg J. Health, social and economical consequences of sleep-disordered breathing: a controlled national study. Thorax. 2011;66(7):560-566.

14. Marin JM, Soriano JB, Carrizo SJ, Boldova A, Celli BR. Outcomes in patients with chronic obstructive pulmonary disease and obstructive sleep apnea: the overlap syndrome. Am J Respir Crit Care Med. 2010;182(3):325-331.

15. Marin JM, Carrizo SJ, Vicente E, Agusti AG. Long-term cardiovascular outcomes in men with obstructive sleep apnoea-hypopnoea with or without treatment with continuous positive airway pressure: an observational study. Lancet. 2005;365(9464):1046-1053.

16. Campos-Rodriguez F, Peña-Griñan N, Reyes-Nuñez N, et al. Mortality in obstructive sleep apnea-hypopnea patients treated with positive airway pressure. Chest. 2005;128(2):624-633.

17. Laaban JP, Mounier L, Roque d'Orbcastel O, et al; ANTADIR Working group "CV risk in OSAS"; CMTS; ANTADIR. Cardiovascular risk factors in men and women with obstructive sleep apnoea syndrome. Respir Med. 2010;104(7):1063-1068.

18. Campos-Rodriguez F, Martinez-Garcia MA, de la Cruz-Moron I, Almeida-Gonzalez C, Catalan-Serra P, Montserrat JM. Cardiovascular mortality in women with obstructive sleep apnea with or without continuous positive airway pressure treatment: a cohort study. Ann Intern Med. 2012;156(2):115-122.

19. Ou Q, Gao XL, Tian XT, He CH, Cen RJ, Chen YC. [Investigation on long-term efficacy of CPAP treatment for the elderly with obstructive sleep apnea syndrome]. Zhonghua Jie He He Hu Xi Za Zhi. 2010;33(5):341-343. Chinese.

20. Kobayashi M, Namba K, Tsuiki S, Matsuo A, Sugiura T, Inoue Y. Clinical characteristics in two subgroups of obstructive sleep apnea syndrome in the elderly: comparison between cases with elderly and middle-age onset. Chest. 2010;137(6):1310-1315.

21. Johansson P, Alehagen U, Ulander M, Svanborg E, Dahlström U, Broström A. Sleep disordered breathing in community dwelling elderly: associations with cardiovascular disease, impaired systolic function, and mortality after a six-year follow-up. Sleep Med. 2011;12(8):748-753.

22. Marrone O, Lo Bue A, Salvaggio A, Dardanoni G, Insalaco G Comorbidities and survival in obstructive sleep apnoea beyond the age of 50. Eur J Clin Invest. 2013;43(1):27-33.

23. Jennum P, Ibsen R, Kjellberg J. Morbidity prior to a diagnosis of sleepdisordered breathing: a controlled national study. J Clin Sleep Med. 2013;9(2):103-108.

24. Sundararajan V, Henderson T, Perry C, Muggivan A, Quan H, Ghali WA. New ICD-10 version of the Charlson comorbidity index predicted inhospital mortality. J Clin Epidemiol. 2004;57(12):1288-1294.

25. Jennum P, Ibsen R, Kjellberg J. Social consequences of sleep disordered breathing on patients and their partners: a controlled national study. Eur Respir J. 2014;43(1):134-144.
26. Jennum P, Ibsen R, Kjellberg J. Morbidity and mortality in children with obstructive sleep apnoea: a controlled national study. Thorax. 2013;68(10):949-954.

27. Charlson ME, Pompei P, Ales KL, MacKenzie CR. A new method of classifying prognostic comorbidity in longitudinal studies: development and validation. J Chronic Dis. 1987;40(5):373-383.

28. Nuttall M, van der Meulen J, Emberton M. Charlson scores based on ICD-10 administrative data were valid in assessing comorbidity in patients undergoing urological cancer surgery. J Clin Epidemiol. 2006;59(3):265-273.

29. McNicholas WT, Bonsigore MR, Bonsignore MR; Management Committee of EU COST ACTION B26. Sleep apnoea as an independent risk factor for cardiovascular disease: current evidence, basic mechanisms and research priorities. Eur Respir J. 2007;29(1):156-178.

30. Punjabi NM, Caffo BS, Goodwin JL, et al. Sleep-disordered breathing and mortality: a prospective cohort study. PLoS Med. 2009;6(8): e1000132.

31. Ciccone MM, Scicchitano P, Zito A, et al. Correlation between inflammatory markers of atherosclerosis and carotid intima-media thickness in obstructive sleep apnea. Molecules. 2014;19(2):1651-1662.

32. Rao M, Rajda G, Uppuluri S, Beck GR, Liu L, Bisognano JD. The role of continuous positive airway pressure in the treatment of hypertension in patients with obstructive sleep apnea-hypoapnea syndrome: a review of randomized trials. Rev Recent Clin Trials. 2010;5(1):35-42.

33. Dorkova Z, Petrasova D, Molcanyiova A, Popovnakova M, Tkacova R. Effects of continuous positive airway pressure on cardiovascular risk profile in patients with severe obstructive sleep apnea and metabolic syndrome. Chest. 2008;134(4):686-692.

34. Ciccone MM, Favale S, Scicchitano P, et al. Reversibility of the endothelial dysfunction after CPAP therapy in OSAS patients. Int J Cardiol. 2012;158(3):383-386.

35. Jennum P, Riha RL. Epidemiology of sleep apnoea/hypopnoea syndrome and sleep-disordered breathing. Eur Respir J. 2009;33(4):907-914.

36. Jennum P, Sjøl A. Snoring, sleep apnoea and cardiovascular risk factors: the MONICA II Study. Int J Epidemiol. 1993;22(3):439-444.

37. Wickwire EM, Collop NA. Insomnia and sleep-related breathing disorders. Chest. 2010;137(6):1449-1463.

38. Nguyên XL, Chaskalovic J, Rakotonanahary D, Fleury B. Insomnia symptoms and CPAP compliance in OSAS patients: A descriptive study using data mining methods. Sleep Med. 2010;11(8):777-784.

39. Luyster FS, Buysse DJ, Strollo PJ. Comorbid insomnia and obstructive sleep apnea: challenges for clinical practice and research. J Clin Sleep Med. 2010;6(2):196-204.

40. Ong JC, Gress JL, San Pedro-Salcedo MG, Manber R. Frequency and predictors of obstructive sleep apnea among individuals with major depressive disorder and insomnia. J Psychosom Res. 2009;67(2):135-141.

41. Martínez-García MA, Campos-Rodríguez F, Catalán-Serra P, et al. Cardiovascular mortality in obstructive sleep apnea in the elderly: role of long-term continuous positive airway pressure treatment: a prospective observational study. Am J Respir Crit Care Med. 2012;186(9): 909-916.

42. Mokhlesi B, Pamidi S, Yaggi HK. Sleep disordered breathing and subjective sleepiness in the elderly: a deadly combination? Sleep. 2011;34(4):413-415.

43. Ancoli-Israel S, Kripke DF, Klauber MR, et al. Morbidity, mortality and sleep-disordered breathing in community dwelling elderly. Sleep. 1996;19(4):277-282.

44. Villar I, Izuel M, Carrizo S, Vicente E, Marin JM. Medication adherence and persistence in severe obstructive sleep apnea. Sleep. 2009;32(5): 623-628. 


\section{Publish your work in this journal}

Nature and Science of Sleep is an international, peer-reviewed, open access journal covering all aspects of sleep science and sleep medicine, including the neurophysiology and functions of sleep, the genetics of sleep, sleep and society, biological rhythms, dreaming, sleep disorders and therapy, and strategies to optimize healthy sleep. The journal welcomes

original research, clinical \& epidemiological studies, reviews \& evaluations, case reports and extended reports. The manuscript management system is completely online and includes a very quick and fair peerreview system, which is all easy to use. Visit http://www.dovepress.com/ testimonials.php to read real quotes from published authors.

Submit your manuscript here: http://www.dovepress.com/nature-and-science-of-sleep-journa| 